\title{
Quantification of lacrimal function after D-shaped field irradiation for retinoblastoma
}

\author{
S M Imhof, P Hofman, K E W P Tan
}

\begin{abstract}
To study the quantitative effects of megavoltage external beam irradiation in a $D$-shaped field in patients with retinoblastoma, biomicroscopy was performed in 61 patients and tear function tests (Schirmer-lactoferrin and lysozyme tests) on 45 eyes in 34 irradiated patients. The results were compared with those obtained in 25 non-irradiated control eyes. The Schirmer test was significantly diminished $(\mathbf{p}<0.001)$ in irradiated eyes, as were the lactoferrin and lysozyme values $(p<0.001)$. A mild to severe keratitis was found in 17 of the 61 patients (28\%). A significant correlation $(p<0.005)$ was found between the severe keratitis and the mean Schirmer values; the mean lactoferrin and lysozyme values were diminished in all patients but did not correlate significantly with the corneal abnormalities. These quantitative data, obtained in patients treated for retinoblastoma, affirm the qualitative data found in patients irradiated for other reasons such as orbital or sinus tumours. Irradiation for retinoblastoma is not a harmless treatment and serious late side effects have to be considered.

(Br F Ophthalmol 1993; 77: 482-484)
\end{abstract}

In the past two decades the general treatment for children with retinoblastoma is megavoltage irradiation with a D-shaped field. ' If there is any question about the residual tumour activity, irradiation is followed by light coagulation and/ or cryotherapy. The tumour control of children thus treated is more than $90 \% .^{2-4}$ However, the late side effects of irradiation of young growing tissues such as orbital growth retardation, second primary tumours, cataract, radiation retinopathy, and tear dysfunction are quite severe. ${ }^{\text {s-9 }}$ With megavoltage external beam irradiation in a $\mathrm{D}$-shaped field these late side effects could theoretically be reduced, ${ }^{10}$ but until now the late side effects of irradiation for retinoblastoma have never been recorded quantitatively. We therefore performed a retrospective study to evaluate the quantitative late effects of megavoltage external beam radiotherapy in a D-shaped field in patients with retinoblastoma.

\section{Patients and methods}

\section{PATIENTS}

From 1971 to 1988,96 retinoblastoma patients were treated with radiotherapy in a D-shaped field at the Utrecht University Hospital. Of these 96 patients, eight died of a second primary tumour, 17 patients were not reached for follow up, and 10 very young children who needed examination under anaesthesia were excluded. Examination was not performed on orbits with a prosthesis after primary or secondary enucleation. Secondary enucleation has never been performed because of corneal problems after irradiation, so 61 patients were examined with biomicroscopy, of whom 34 patients underwent tear function tests in 45 irradiated eyes. The remaining 27 patients were excluded because of non-cooperation with the tear function tests.

As a control we used nine non-irradiated fellow eyes and 16 eyes in eight patients with ocular motility disorders.

The age of the retinoblastoma patients ranged from 3.5-24 years (mean 9.5), and of the control group from 6-17 years (mean 11). Thirty six patients were treated for bilateral and 25 for unilateral retinoblastoma. The follow up time varied from 34 months to 209 months (mean 86).

\section{METHODS}

\section{Irradiation technique}

Radiation therapy is carried out on a $6 \mathrm{MV}$ or $8 \mathrm{MV}$ linear accelerator using a lateral $\mathrm{D}$-shaped field of $26 \times 32 \mathrm{~mm}$. This D-shaped field is especially contoured to irradiate the entire retina with sparing of the radiosensitive lens as much as possible. Accurate positioning of the eye in the sharply collimated treatment field is easily performed by magnetic fixation of the eye to the beam defining collimator by use of a low vacuum contact lens. The axial dimensions of each eye are determined by ultrasonic biometry before treatment to ascertain the exact volume to be irradiated. The applied radiation dose is normalised at a minimum tumour dose of $45 \mathrm{~Gy}$ given in 15 fractions of $3 \mathrm{~Gy}$ at three fractions a week. ${ }^{110}$

\section{STATISTICAL METHODS}

To compare the outcome of the tear function tests and the biomicroscopy findings we used the two sample $t$ test, the multivariate analysis, and the Mann-Whitney U test.

\section{Slit-lamp biomicroscopy}

Objectively, extensive slit-lamp biomicroscopy provided information on corneal epithelial scarring, punctate keratitis, and filamentosal keratitis. We divided our findings into mild keratitis (mild punctate keratitis and conjunctival redness) and severe keratitis (keratopathy and/or large epithelial punctate and/or filamentosal keratitis). 
Table 1 Biomicroscopy findings in irradiated patients

Slit-lamp examination

No corneal abnormalities 44 Mild keratitis

Severe keratitis

Total

Tear function tests

All tear function tests were performed without anaesthetic eye drops and with both eyes closed.

Schirmer tear test strips. Those used were from Clement Clarke International Ltd (London), normal values $>15 \mathrm{~mm} / 5$ minutes. ${ }^{11-13}$ In Schirmer's blotting paper test one end of a strip of filter paper, $0.5 \mathrm{~cm} \times 3.5 \mathrm{~cm}$, is inserted into the lower conjunctival fornix folded at right angles over the ciliary body of the lid where it is left in position: the normal secretion ought to moisten at least $1.5 \mathrm{~cm}$ of the strip as measured from the fold in 5 minutes. The test is rough, but it provides an indication, at least, of excessive lacrimation or of marked hyposecretion or absence of tears. ${ }^{11}$

Lactoplate. The one used was from JDC, Culemborg (The Netherlands). Lactoplate contains a tear lactoferrin immunoassay test with rabbit antiserum to human lactoferrin in an agarose gel. It quantifies the lactoferrin concentration in tear fluid by radial immunodiffusion (Mancini test). Normal values are $>1.0 \mathrm{mg} / \mathrm{ml} .{ }^{12}$ A small round filter paper is placed in the lower conjunctival fornix. After 5 minutes the filter paper is taken out and put on the special test agarose gel. The Lactoplate is kept for 48-72 hours at a temperature of $21^{\circ} \mathrm{C}$ when the diffusion circles are measured. The lactoferrin concentration is measured by extrapolation of the diameter on the Lactoplate.

The lysozyme test. This is performed in the same way as the lactoferrin, with a round testing . filter paper in the lower conjunctival fornix. It is then sent to the microbiology department. The patient's filter paper is put on a DST (diagnostic

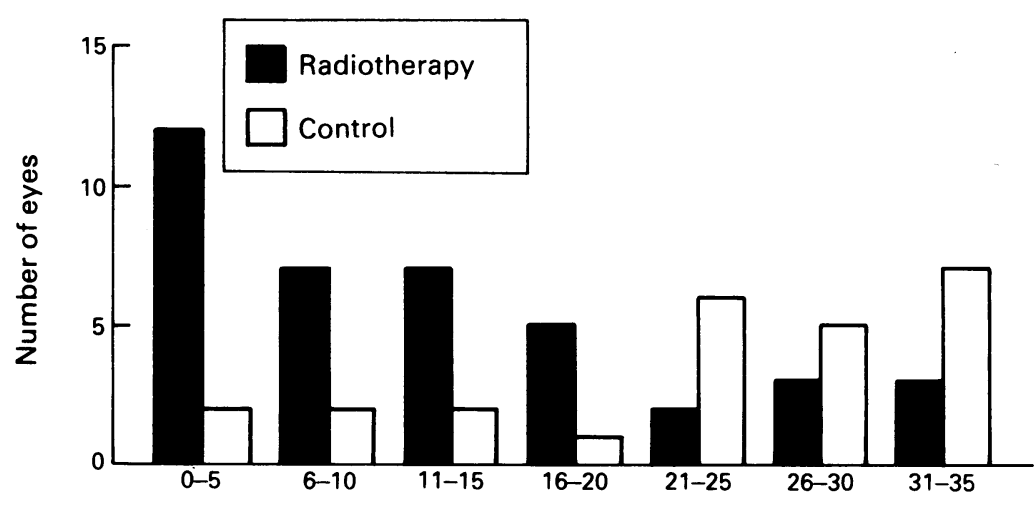

Schirmer values ( $\mathrm{mm}$ in 5 minutes)

Figure 1 Schirmer test findings in number of irradiated and non-irradiated eyes.

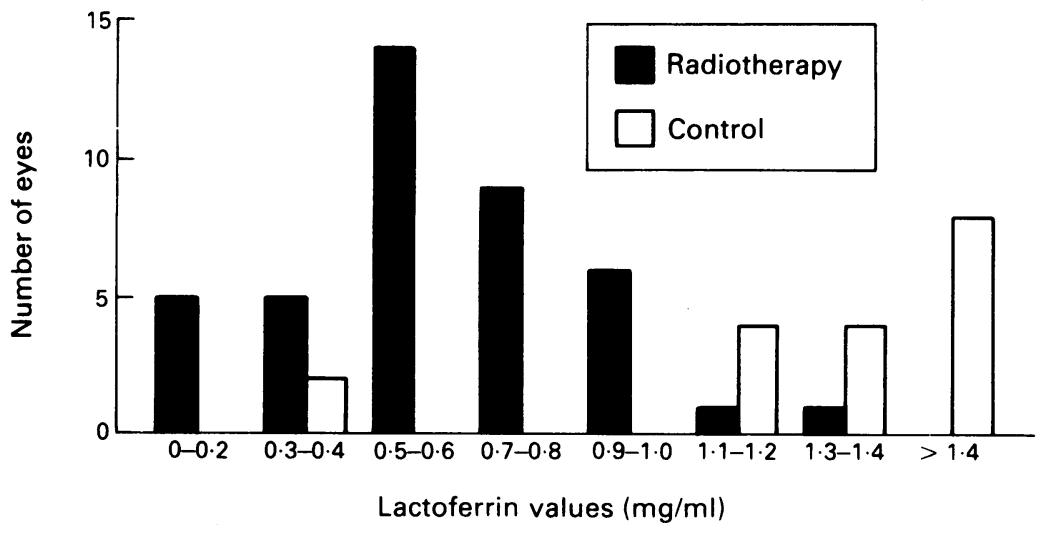

Figure 2 Lactoferrin testing values in number of irradiated and non-irradiated eyes
Table 2 Biomicroscopy findings and mean tear function values

\begin{tabular}{llll}
\hline Mean values & $\begin{array}{l}\text { No corneal } \\
\text { abnormalities }\end{array}$ & $\begin{array}{l}\text { Mild } \\
\text { keratitis }\end{array}$ & $\begin{array}{l}\text { Severe } \\
\text { keratitis }\end{array}$ \\
\hline Schirmer $(\mathrm{mm})$ & 16 & 14 & 4.6 \\
Lysozyme $(\mathrm{mg} / \mathrm{ml})$ & 1.185 & 0.860 & 0.620 \\
Lactoferrin $(\mathrm{mg} / \mathrm{ml})$ & 0.6 & 0.5 & 0.5 \\
\hline
\end{tabular}

sensitivity test) agarose gel with a testing microbe (Micrococcus lysodeikticus). The control is done with lysozyme extracted from 'Huehnereiweiss' which is put on DST agar gel to make a standard curve. Normal values are $1.425 \mathrm{mg} / \mathrm{ml}^{12}{ }^{14}$

\section{Results}

\section{SLIT-LAMP BIOMICROSCOPY}

This was performed on 61 patients and the results are given in Table 1 . Of 61 patients, 44 did not have corneal abnormalities, 10 patients had a mild keratitis, and seven had a severe keratitis.

Table 2 shows the findings of the slit-lamp biomicroscopy related to the mean values of the Schirmer and laboratory tests (the tests could not be performed in every patient). In five patients (seven eyes) with a severe keratitis Schirmer tests were performed and the mean Schirmer values were significantly diminished (Mann-Whitney U test, $\mathrm{p}<0.005$ ). In 27 patients (32 eyes) without corneal abnormalities or a mild keratitis the mean Schirmer values were within the lower normal range and did not significantly correlate. In all investigated patients the mean lactoferrin and lysozyme concentrations were diminished but no significant correlation was found with the corneal abnormalities.

SCHIRMER TEST

The Schirmer values measured in 39 irradiated eyes ( 31 patients) ranged between 0 and $35 \mathrm{~mm}$ in 5 minutes, mean value $14 \mathrm{~mm}$. In 25 nonirradiated eyes ( 17 patients) the Schirmer values ranged between 3 and $40 \mathrm{~mm}$ in 5 minutes, mean $23 \mathrm{~mm}$. The difference between irradiated and non-irradiated patients was significant (two sample $t$ test, $\mathrm{p}<0 \cdot 001$ ) (Fig 1 ).

\section{LACTOFERRIN CONCENTRATION}

In 31 patients with 41 irradiated eyes the lactoferrin concentration ranged between 0 and $1 \cdot 3$ $\mathrm{mg} / \mathrm{ml}$, mean $0.6 \mathrm{mg} / \mathrm{ml}$. In 18 non-irradiated eyes (14 patients) the lactoferrin concentration ranged from 0.4 to $2.2 \mathrm{mg} / \mathrm{ml}$, mean $1.3 \mathrm{mg} / \mathrm{ml}$. The difference in the lactoferrin concentrations between irradiated and non-irradiated eyes was significant (two sample $t$ test, $\mathrm{p}<0.001$ ) (Fig 2).

\section{LYSOZYME CONCENTRATION}

In 29 patients with 39 irradiated eyes lysozyme concentrations ranged from 0.20 to $2.40 \mathrm{mg} / \mathrm{ml}$, mean $1.02 \mathrm{mg} / \mathrm{ml}$. In 14 patients with 19 normal eyes the lysozyme concentrations were greater, with values between 0.8 and $3.6 \mathrm{mg} / \mathrm{ml}$, mean 


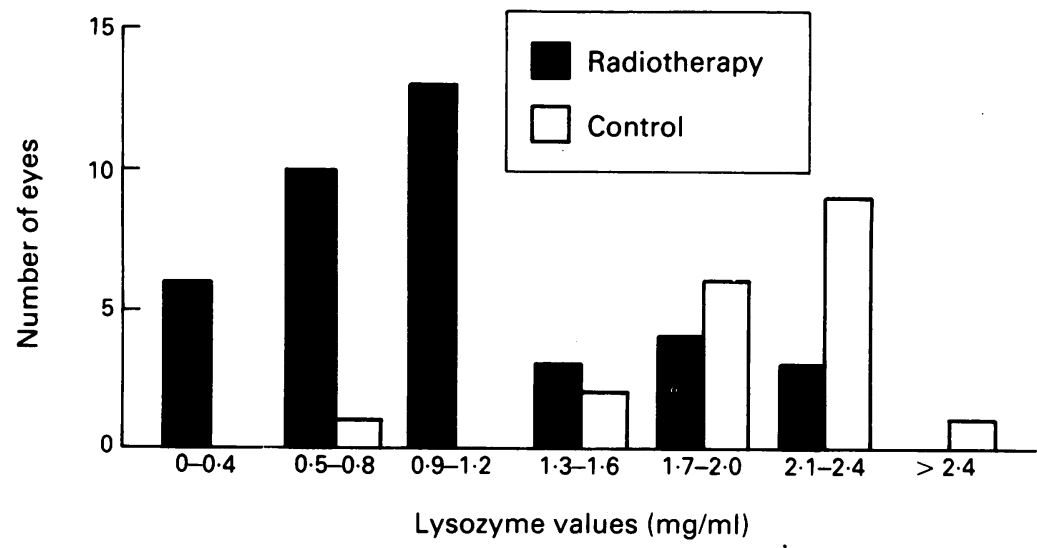

Figure 3 Lysozyme testing values in number of irradiated and non-irradiated eyes

$2 \cdot 2 \mathrm{mg} / \mathrm{ml}$. With respect to the lysozyme concentration the difference between irradiated and non-irradiated eyes was significant (two sample $t$ test, $\mathrm{p}<0.001$ ) (Fig 3).

\section{Discussion}

Late effects on the eye and orbit after ocular or orbital irradiation are well known..$^{5-91516}$ Complications may arise with all forms of radiotherapy, but vary with the different ocular tissues involved and the form of irradiation used. ${ }^{7516}$ Serious sequelae of external beam radiotherapy applied for retinoblastoma in often very young children are: radiation-induced orbital growth retardation, retinopathy, cataract, corneal damaging, and dysfunction of the lacrimal gland. 5691516

Lateral D-shaped external beam irradiation in the treatment of retinoblastoma reduces cataract formation. ${ }^{10}$ In addition, lateral D-shaped external beam irradiation is expected to spare the main and accessory lacrimal glands, because of their position just outside the field of irradiation. ${ }^{10}$ To investigate this hypothesis, we evaluated the quantitative effects on tear function of megavoltage external beam radiotherapy with a D-shaped field in patients with retinoblastoma.

The main and accessory lacrimal glands (of Wolfring and Krause) contribute to the formation of the middle aqueous tear film layer, consisting of water, electrolytes, enzymes, and proteins, such as lactoferrin and lysozyme. ${ }^{112}{ }^{17-19}$ The watery component, lactoferrin and lysozyme, plays an important role in keeping the precorneal tear film stable and preventing the corneal epithelium drying up. ${ }^{1213}$ Lacking of these components will thus result in instability of the tear film and damage to the corneal epithelium, as can be seen in keratitis sicca. ${ }^{11-13} 1718$

In our patients, treated with external beam irradiation with a D-shaped field, we found a significant lessening of tear production (as measured with the Schirmer test) and a significant reduction in tear protein production when compared with a control group (Figs 1, 2, and 3). Although the patient group and the control group are not identical or randomised (which is extremely difficult in this group of patients), we can conclude that the quantitative lacrimal function tests are significantly disturbed in children treated with external beam irradiation as a result of irradiation damage to the main lacrimal gland and, possibly, the accessory glands of Klause lying in the upper conjunctival fornix. ${ }^{19}$ As a consequence, these children have a diminished stability of the tear film and thus may be prone to (sub) epithelial keratopathies. ${ }^{11} 13151719$ In almost 30\% of them these (sub) epithelial keratopathies were found and these lesions appeared to correlate significantly with decreasing Schirmer values. No such a significant correlation was found between the mean lactoferrin and lysozyme concentrations and the presence and severity of the corneal abnormalities, but this may be explained by the fact that the sample size of the patient group with mild or severe keratitis was too small.

We conclude that, although irradiation in patients with retinoblastoma has proved to be a valuable tool in tumour control with excellent survival rates, side effects are still considerable. In evaluating these late side effects we are convinced that a search for irradiation techniques which are as effective in tumour control, but less damaging, should be stimulated.

We acknowledge the help of $\mathrm{Dr} M \mathrm{Ph}$ Mourits.

1 Schipper J. An accurate and simple method for megavoltage radiation therapy of retinoblastoma. Radiother Oncol 1983; 1: $31-41$.

2 Amendola BE, Markoe AM, Augsburger JJ, Karlsson UL, Giblin $M$, Shields JA, et al. Analysis of treatment results in 36 children with retinoblastoma/treated with scleral plaque irradiation. Int F Radiat Oncol Biol Phys 1989; 17: 63-70.

3 Shields JA, Shields CL, Donoso LA, Lieb WE. Changing concepts in the management of retinoblastoma. Surg Rev 1990; $21: 72-6$.

4 Cassady JR, Sagerman RH, Tretter P, Ellsworth RM. Radiation therapy in retinoblastoma. Radiology 1969; 93: 405-9.

5 Messmer EP, Fritze H, Mohr C, Heinrich Th, Sauerwein W, Havers $\mathrm{W}$, et al. Longterm treatment effects in patients with bilateral retinoblastoma: ocular and mid-facial findings. Graefes Arch Clin Exp Ophthalmol 1991; 229: 309-14.

Graefes Arch Clin Exp Ophthalmol 1991; 229: 309-14.
6 Egawa S, Tsukiyama I, Akine Y, Kajiura Y, Ogino T. Suppression of bony growth of the orbit after radiotherapy for retinoblastoma. Radiat Med 1987; 5: 207-11.

7 Cogan DG, Fink R, Donaldson DD. X-ray irradiation of orbital glands of the rabbit. Radiology 1955; 64: 731-7.

8 Karp LA, Streeten BW, Cogan DG. Radiation induced atrophy of the Meibomian glands. Arch Ophthalmol 1979; 97: 303-5.

Pedford MA. Ocular complications after therapeutic irradiation. Br f Ophthalmol 1970; 54: 237-7.

Schipper J. Retinoblastoma, a medical and experimental study. Thesis 1980, Utrecht.

11 Duke-Elder S. Diseases of the outer eye. Part i. 1973: 128-32.

Van Bijsterveld OP. Diagnostic tests in the sicca syndrome. Arch Ophthalmol 1969; 82: $10-4$.

13 Van Bijsterveld OP, Ekdom B. The surface tension of the lacrymal in patients with keratoconjunctivitis sicca. Ophthalmologica 1984; 188: 44-5.

14 Van Bijsterveld OP. Standardisation of the Lysozyme test of a commercially available medium. Arch Ophthalmol 1974; 91 : 432.4.

15 Chan RC, Shukovsky LJ. Effects of irradiation on the eye. Radiology 1976; 120: 673-5.

16 Parsons JT, Fitzgerald CR, Hood I, Ellingwood KE, Bova FJ, Million RR. The effects of irradiation on the eye and optic nerve. Int $\mathcal{F}$ Radiat Oncol Biol Phys 1983; 9: 609-22.

17 Farris RL. Abnormalities of the tears and treatment of dry eyes. In: Kaufman HE, et al, eds. The cornea. Edinburgh: Cyes. In: Kaurman HE, et al, eds. The cornea. Edinburgh:

8 Royer J, Adenis JP, Bernard JA, Metaireau JP, Reny A L'appareil lacrymal. Paris: Masson, 1982: 28-31, 76-81.

19 Jones LT. The lacrimal system and its treatment. Am $\mathcal{f}$ Ophthalmol 1966; 62: 47-60. 